\title{
Drying and Crystallization of Evaporating Sodium Nitrate Aerosol Droplets
}

\author{
F. K. A. Gregson ${ }^{1, *}$, J. F. Robinson², R. E. H. Miles ${ }^{1}$, C. P. Royall ${ }^{1,2}$ and J. P. Reid ${ }^{1}$
}

1 School of Chemistry, University of Bristol, Bristol, BS8 1TS

2 School of Physics, University of Bristol, Bristol, BS8 1TS

* florence.gregson@ bristol.ac.uk

\section{Supporting Information}
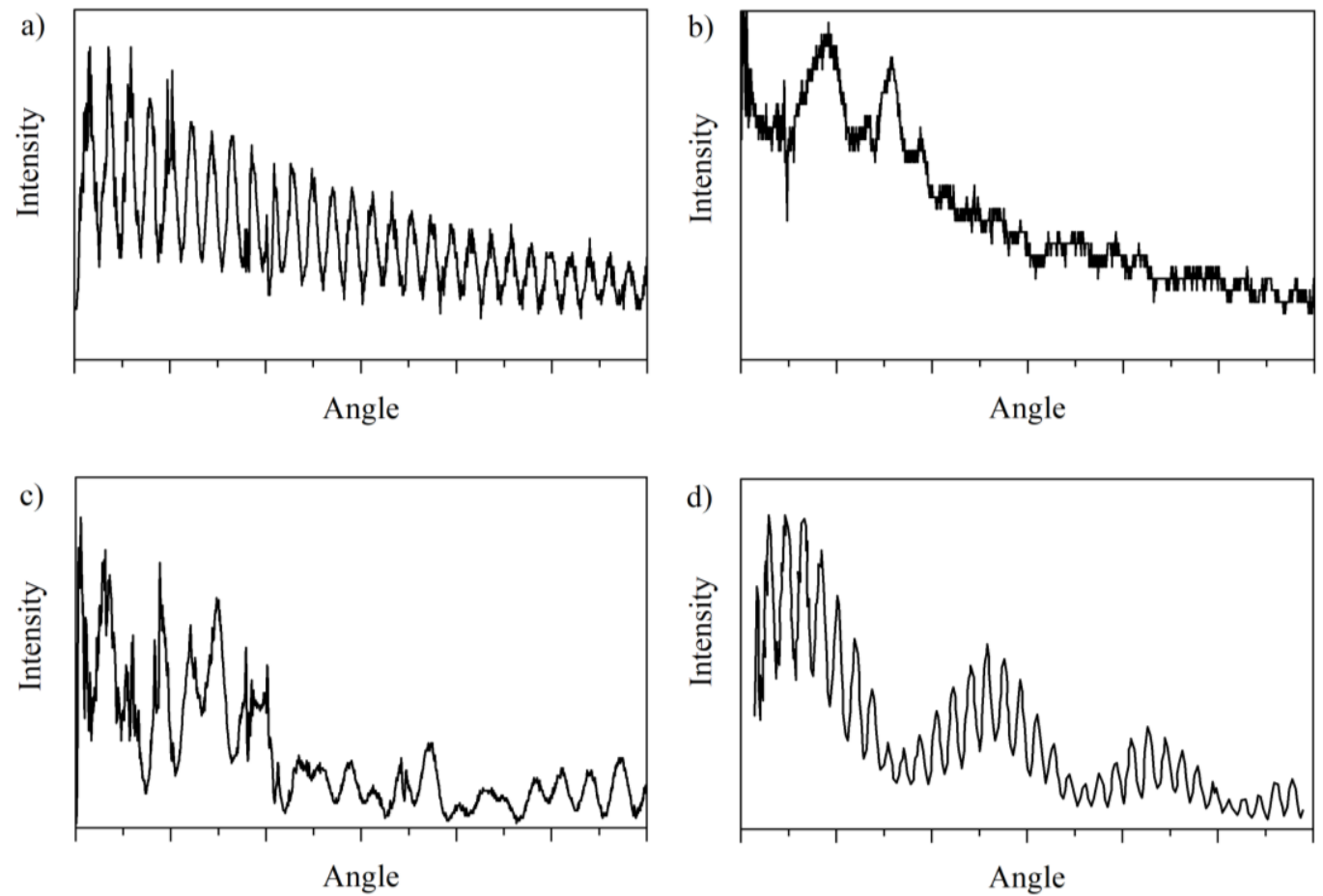

Figure S1: Examples of the light-scattering caused by droplets exhibiting different morphologies: a) A homogeneous phase function from a pure water droplet, b) a dried and crystalline $\mathrm{NaCl}$ particle, c) an aqueous $\mathrm{NaNO}_{3}$ droplet that has nucleated small nuclei but not undergone complete crystallization, d) a dodecanol-water droplet (from Haddrell et al. $\left.{ }^{1}\right)$ 


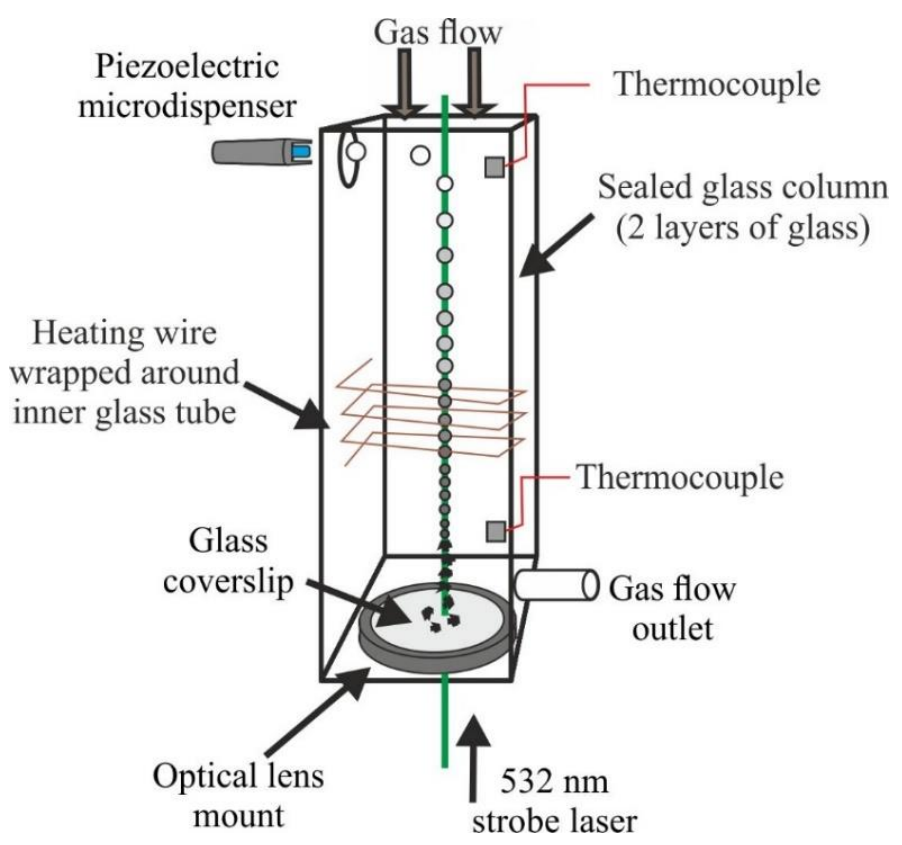

Figure S2: A schematic diagram of the setup of the falling droplet column instrument, used in this work in parallel to EDB measurements to collect dried particles on a glass slide, in order to study the dried particle morphology. 

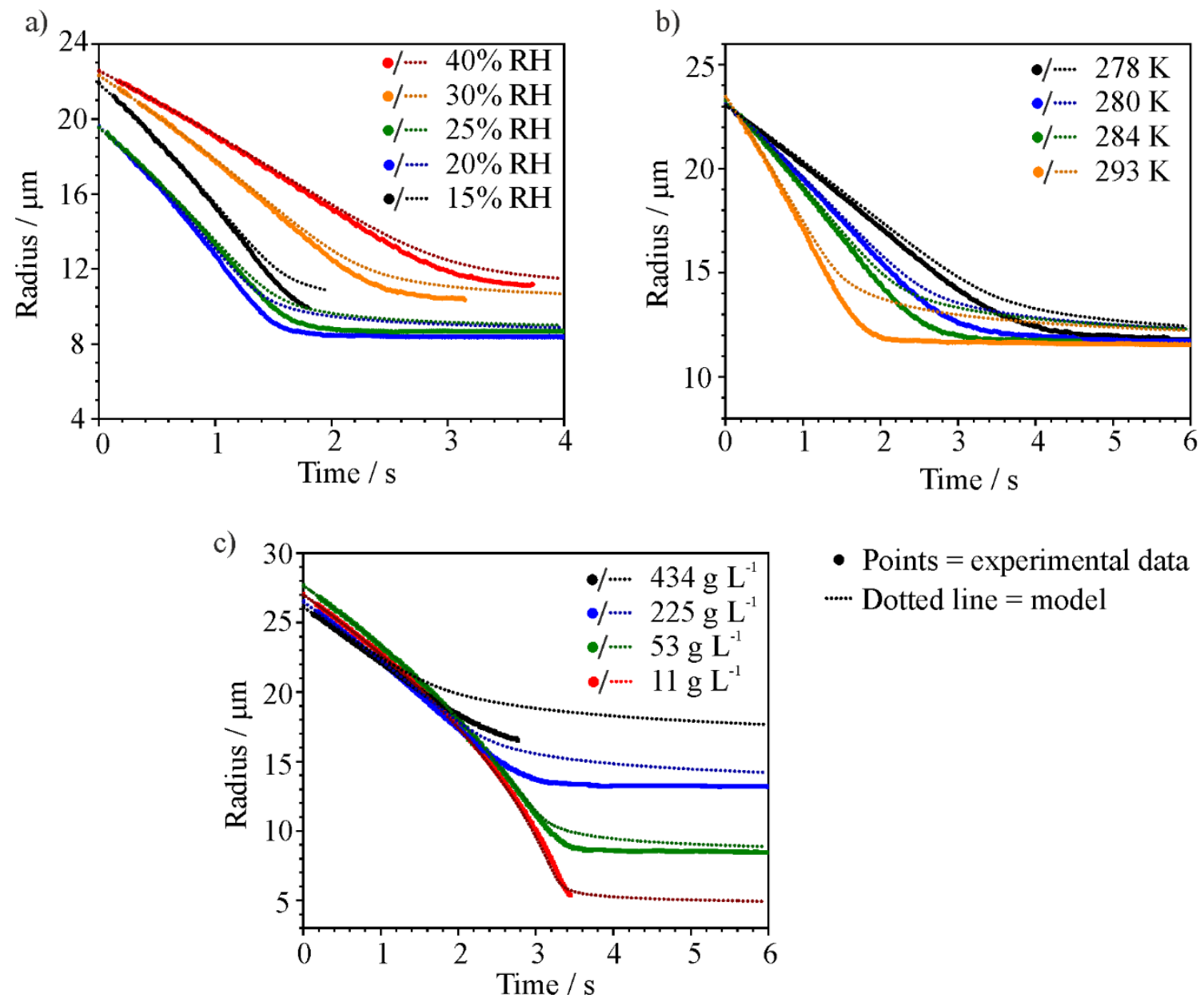

- Points $=$ experimental data

...... Dotted line $=$ model

Figure S3: A comparison between the droplet radii during evaporation (1 droplet from each dataset shown as an example) obtained through experimental CK-EDB measurements and the fitted model. a) The experimental data is that shown in Fig. 6a, i.e. NaNO3 droplets (12.5\% wt/wt) evaporating in the CK-EDB at $293 \mathrm{~K}$ at varying RHs. b) The experimental data is that shown in Fig. 8a, i.e. $20 \%$ NaNO3 droplets evaporating into $0 \%$ RH at varying gas-phase temperatures in the CK-EDB. c) The experimental data is that shown in Fig. 9a, i.e. NaNO3 droplets evaporating into $0 \% \mathrm{RH}$ at $284.5 \mathrm{~K}$ with varying starting concentrations. 

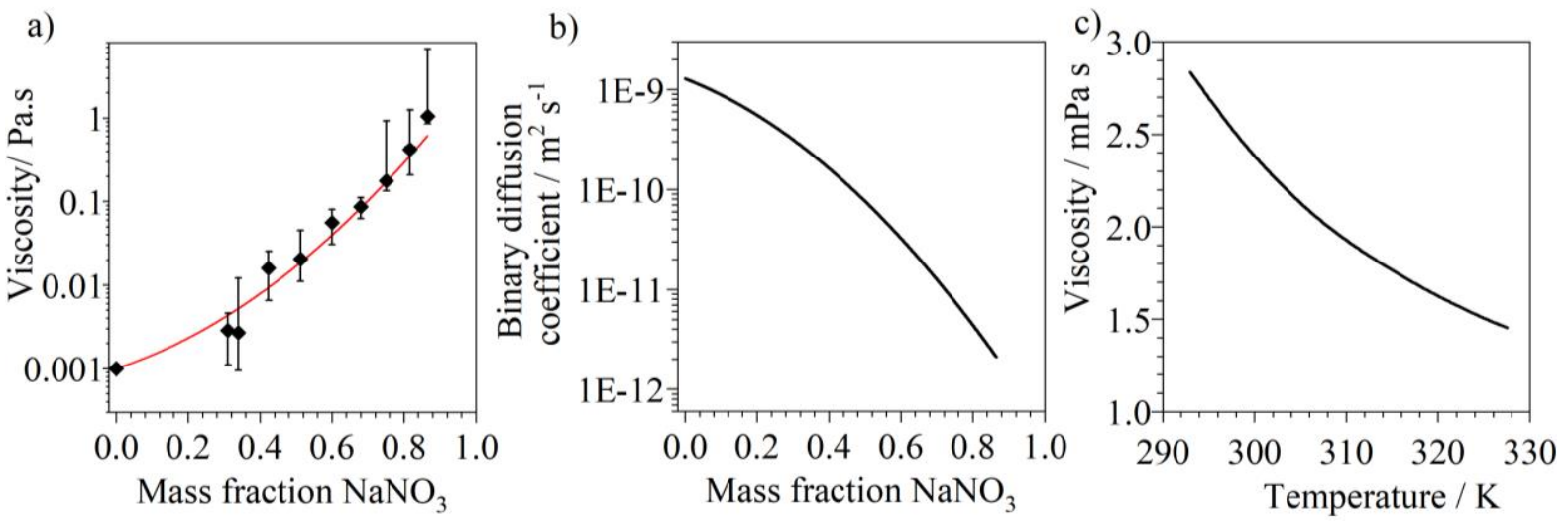

Figure S4: a) The viscosity of aqueous $\mathrm{NaNO}_{3}$ at $293 \mathrm{~K}$ as a function of the mass fraction as used in this work, showing the best fit line. Data are plotted from Baldelli et al. ${ }^{2}$ b) The binary diffusion coefficient of aqueous $\mathrm{NaNO}_{3}$ solutions at $293 \mathrm{~K}$, calculated using a Stokes-Einstein relation using the viscosity fit from a) and a Stokes radius of $0.167 \mathrm{~nm}$. c) The temperature-dependent viscosity of a solution of $0.405 \mathrm{MFS} \mathrm{NaNO}_{3}$. Data is plotted from Mahiuddin et al. ${ }^{3}$

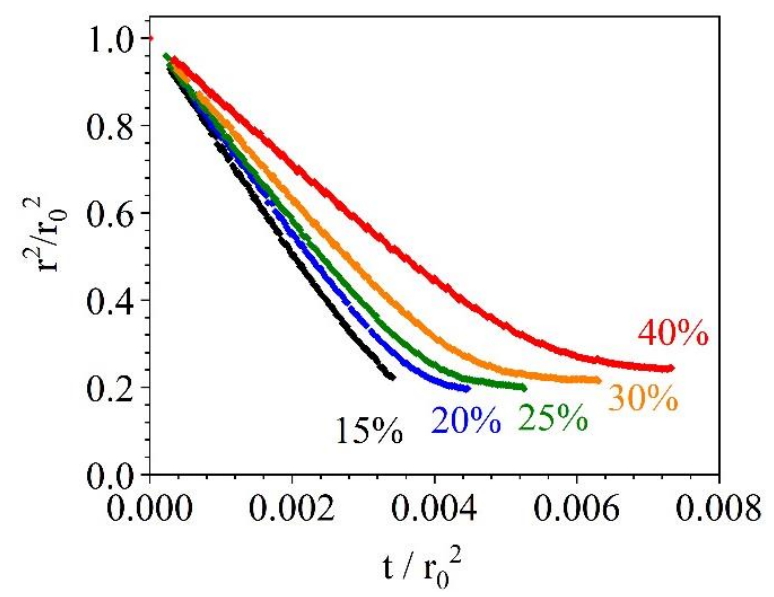

Figure S5: Evolution of droplet radius for $\mathrm{NaNO}_{3}$ droplets $(12.5 \%$ w/w $)$ evaporating in the CK-EDB at $293 \mathrm{~K}$ at varying RHs (as indicated on the figure); i.e. the same data as that plotted in Fig. 6a, but with the data normalised with respect to the initial droplet radius, $r_{0}$.

\section{References}

(1) Haddrell, A.; Rovelli, G.; Lewis, D.; Church, T.; Reid, J. P. Identifying Time-Dependent Changes in the Morphology of an Individual Aerosol Particle from Their Light Scattering Patterns. Aerosol Sci. Technol. 2019, 53, 1334-1351.

(2) Baldelli, A.; Power, R. M.; Miles, R. E. H.; Reid, J. P.; Vehring, R. Effect of Crystallization Kinetics on the Properties of Spray Dried Microparticles. Aerosol Sci. Technol. 2016, 50, 693704.

(3) Mahiuddin, S.; Ismail, K. Temperature and Concentration Dependence of the Viscosity of Aqueous Sodium Nitrate and Sodium Thiosulphate Electrolytic Systems. Fluid Phase Equilib. 1996, 123, 231-243. 